\title{
INOVAÇÃO SOCIAL EM REDE NO ÂMBITO DE UM INSTITUTO BRASILEIRO
}

NETWORK SOCIAL INNOVATION IN A BRAZILIAN INSTITUTE

Recebido em 07.03.2019 Aprovado em 03.06.2019

Avaliado pelo sistema double blind review DOI: https://doi.org/10.12712/rpca.v13i3.28198

\author{
Naldeir dos Santos Vieira \\ naldeir.vieira@ufvim.edu.br \\ Programa de Pós-Graduação em Administração Pública - PPGAP/Universidade Federal dos Vales do \\ Jequitinhonha e Mucuri - UFVJM - Teófilo Otoni/Minas Gerais, Brasil \\ ORCID: http://orcid.org/000-0001-5624-8345
}

\section{Allan Claudius Queiroz Barbosa}

allan@,ufmg.br

Faculdade de Ciências Econômicas da Universidade Federal de Minas Gerais - FACE/UFMG - Belo

Horizonte/Minas Gerais, Brasil

ORCID: http://orcid.org/0000-0003-1266-5168

\section{Cristina Parente}

cparente@letras.up.pt

Departamento de Sociologia/Universidade do Porto - UP - Porto/Porto, Portugal

ORCID: htttp://orcid.org/0000-0002-75007050

\section{Resumo}

Esse estudo busca analisar a importância das redes interorganizacionais para o desenvolvimento de inovações sociais por meio de estudo de caso qualitativo realizado sobre o Instituto Brasileiro de Desenvolvimento e Sustentabilidade (IABS), com sede na cidade de Brasília. Optou-se pela observação direta, análise documental e realização de entrevistas semiestruturadas como técnicas de coleta de dados. Diante da complexidade de grande parte dos problemas enfrentados pelo Instituto, as redes interorganizacionais foram consideradas como indispensáveis na definição e implementação de estratégias cujos resultados se tornaram sustentáveis no longo prazo e no alcance de maior variedade de dimensões impactadas.

Palavras-chave: Inovação social. Redes Interorganizacionais. Terceiro Setor.

\begin{abstract}
This study aims to analyze the importance of interorganizational networks for the development of social innovations through a qualitative case study carried out on the Instituto Brasileiro de Desenvolvimento e Sustentabilidade (IABS), based in the city of Brasília. We opted for direct observation, documentary analysis and semi-structured interviews as data collection techniques. Faced with the complexity of most of the problems faced by the Institute, interorganizational networks were considered indispensable in the definition and implementation of strategies whose results became sustainable in the long term and reach a greater variety of dimensions impacted.
\end{abstract}

Keywords: Social innovation. Interorganizational Networks. Third sector. 


\section{Introdução}

Esse artigo analisa a importância das redes interorganizacionais para o desenvolvimento de inovações sociais, tendo como campo de estudo as ações e projetos articulados no âmbito do Instituto Brasileiro de Desenvolvimento e Sustentabilidade (IABS) com sede em Brasília - Distrito Federal. Trata-se de um estudo alternativo aos diversos realizados sobre inovação, já que esse tema tem sido estudado, principalmente, sob o prisma da inovação tecnológica (BAUMGARTEN, 2008).

Ampliar as análises a outros tipos de inovação tornou-se necessário diante do fato de o crescimento econômico resultante do desenvolvimento científico e das inovações tecnológicas não ter sido suficiente para que antigos problemas sociais fossem resolvidos quando considerada a garantia da qualidade de vida da população como um todo. Além disso, inúmeras foram as ações desenvolvimentistas que tiveram efeitos contraproducentes, refletindo na ampliação das desigualdades sociais e na degradação ambiental (DOWBOR, 2007). Em decorrência, problemas apontados por Moulaert et al. (2013), como fome, pobreza, conflitos, prisão política, poluição, analfabetismo, opressão econômica, racismo, diferenças entre classes sociais, discriminação de gênero e alterações climáticas, surgem a todo o momento, apesar dos avanços da ciência e da tecnologia.

Diante da complexidade desses problemas, intensificou-se o debate sobre a necessidade de rever o modelo de crescimento econômico, sobretudo no que se refere ao desenvolvimento de inovações que, além de considerarem a recuperação e ou redução dos impactos ao meio ambiente, permitem seu direcionamento às populações historicamente colocadas à margem do acesso a bens e serviços. Este debate dá ênfase às limitações da inovação tecnológica desenvolvida e circunscrita em um contexto mercadológico sob o pano de fundo da racionalidade puramente instrumental, que se utiliza da expropriação de valor como meio para garantir a lucratividade.

O debate citado remete à relação entre "produção de ciência, tecnologia, inovação e necessidades sociais e à importância crescente da apropriação por parte de diferentes atores sociais de conhecimento científico que possa ser incorporado socialmente para a resolução de problemas, gerando inovação social" (BAUMGARTEN, 2008, p. 104). Tais inovações buscam a conexão entre satisfação de necessidades básicas, melhoria da qualidade do meio ambiente, inovação nas relações sociais, governança, empoderamento e justiça social (MEHMOOD; PARRA, 2013).

Nessa perspectiva, os conceitos de tecnologia e inovação estão relacionados às necessidades humanas e às potencialidades, tendo em vista as possibilidades para a inclusão social. A construção do conhecimento pautada na sustentabilidade econômica e social busca a articulação entre produção de conhecimento e potencialidades e necessidades locais, dando ênfase à relevância das redes que articulam pesquisadores, demais atores relacionados à produção de conhecimento, e a sociedade para o desenvolvimento de tecnologias e inovações.

Tal perspectiva "é o ponto de partida para a busca de mediações entre as instâncias de produção do conhecimento científico e a sociedade” (BAUMGARTEN, 2006 apud BAUMGARTEN, 2008, p. 107). Mediações estas que podem ser estabelecidas por meio da articulação de redes que aproximem academia e sociedade civil, fazendo com que o desenvolvimento da ciência e da tecnologia esteja direcionado à resolução de problemas inerentes à exclusão social e à baixa qualidade de vida de populações marginalizadas. Nestas redes, as Organizações da Sociedade Civil Sem Fins Lucrativos (OSCs) assumem importante papel por atuarem diretamente com o público citado, ora prestando assistência social, ora promovendo ações direcionadas à inclusão social, complementando ou atendendo a imperativos não supridos pelo Estado ou pelo mercado (DEFOURNY, 2009).

No entanto, Bouchard (2012) questiona se as OSCs sozinhas possuem condições de resolver problemas em grande escala. Para o autor, os esforços e o envolvimento são necessários a partir da sociedade como um todo, reforçando a necessidade de parcerias neste âmbito. Da perspectiva de Oliveira e Breda- 
Vázquez (2012), aspectos relevantes relacionados à sustentabilidade e difusão da inovação social ainda estão incompreendidos, principalmente os que dizem respeito às condições ambientais que favorecem a sustentabilidade e difusão da inovação social e às novas formas de alinhar interesses e atores diversos e de combinar os diferentes atores e recursos disponíveis para a obtenção de novas respostas aos problemas enfrentados. Com efeito, este estudo busca responder ao seguinte questionamento: qual a importância das redes interorganizacionais para o desenvolvimento de inovações sociais, tomando como pano de fundo as ações e projetos desenvolvidos pelo IABS?

A escolha das práticas desenvolvidas pelo IABS como campo de análise dá-se pela sua inserção no nordeste brasileiro onde articula o desenvolvimento de ações socialmente inovadoras voltadas, principalmente, para a gestão de recursos hídricos em todo o semiárido, por meio do trabalho em rede com inúmeras associações locais, instituições de ensino, agências de desenvolvimento e instituições públicas de diferentes níveis.

\section{Inovação Social e Redes Interorganizacionais}

Desde sua significação inicial, dada por Schumpeter, nos anos de 1930, o construto inovação tem forte conotação com a obtenção de valor econômico, vindo posteriormente a resultar em variadas significações com a contribuição de uma diversidade de autores. A inovação passa a ser definida como um processo que desencadeia a geração e a adoção de novas ideias, práticas e artefatos, o desenvolvimento de novos procedimentos, soluções, produtos e métodos de comercialização e a combinação entre criatividade e risco, cujos resultados alteram o setor econômico como um todo (BIGNET'TI, 2011).

O entendimento da inovação esteve fortemente relacionado à inovação tecnológica, referindo-se à introdução de um novo bem, ou de uma nova qualidade de um bem, e de um novo método de produção no ramo específico da indústria de transformação. Porém, mais recentemente novos conceitos vêm ganhando notoriedade, como os de inovação organizacional ou administrativa, de mercado ou de marketing e de inovação social (BIGNETTT, 2011).

Parente et al. (2014) fazem uma análise etimológica da palavra inovação, considerada como originária do latim innovare, com os radicais in significando "em" e novus significando "novo" ou "recente", resultando no significado de "tornar novo". No entanto, o novo, na perspectiva de Frazão et al. (2015), tem uma conotação mais específica quando o objeto de análise é a inovação social. Neste âmbito, a novidade não está relacionada à necessidade de ser única ou original. Ela precisa ser percebida como nova para o usuário ou para o contexto em que foi desenvolvida ou apropriada. Desse modo, ela não precisa necessariamente ser nova em si, mas nova para o território, setor, ou área de atuação. Além disso, Frazão et al. (2015) destacam um segundo critério, que é a melhoria da qualidade de vida, ao ser mais eficaz ou mais eficiente do que as alternativas preexistentes. A esta lista de melhorias Baumgarten (2008) adiciona a necessidade de ser mais sustentável ou mais justa. Como sustentáveis estão as ações voltadas para a preservação ou manutenção do meio ambiente e, como justas, as ações que buscam reduzir as desigualdades sociais.

Esta abordagem da inovação social, de modo mais específico, adquiriu maior relevo na última metade do século XX. Foi reforçada pelas falhas e inconsistências do modelo de crescimento neoliberal, que se alargou a todo o mundo desde 1980 (KLEIN, 2013), e pelas novas abordagens sobre o processo inovativo, tendo em vista o estímulo ao desenvolvimento social (BIGNETTI, 2011). Portanto, a inovação social responde a um contexto de crise ou à incapacidade do quadro institucional para encontrar respostas satisfatórias para os problemas agudos ou a um contexto provocado por situações inteiramente novas (KLEIN et al., 2012). Como resultado, o termo inovação social passou a fazer parte das agendas governamentais e de alguns pesquisadores/grupos de pesquisa, multiplicando-se hoje as abordagens à temática. 
O novo conceito tem como aspecto distintivo as "novas formas de fazer as coisas com o fim explícito de rearranjar os papéis sociais ou de dar outras respostas para situações sociais insatisfatórias e problemáticas" (RODRIGUES, 2006, p. 3). O foco de análise passa a ser as ações que objetivam satisfazer as necessidades humanas ainda não supridas pelos sistemas públicos ou organizacionais privados.

Por mais que os conceitos de inovação social abranjam uma diversidade prática, podem ser identificadas na literatura duas correntes teóricas principais. A primeira explora os processos organizacionais e sociais que produzem a inovação, tais como, indivíduos, estruturas organizacionais, contextos ambientais e fatores sociais e econômicos. A segunda explora a inovação social como resultado que se manifesta em novos produtos, recursos e métodos de produção, analisando suas fontes e consequências econômicas. Assim, dividem-se, principalmente, na análise da inovação social como processo e da inovação social como resultado.

Não obstante as duas correntes citadas, identificou-se uma diversidade de estudos que abordam tanto a dimensão do processo quanto a do resultado da inovação social. Além disso, destacam-se aqueles relacionados aos modelos de intervenção social, que, na visão de Parente et al. (2014), integram as dimensões analíticas do processo e do resultado ou produto.

Ressalta-se que inicialmente as noções de inovação social estavam associadas às ações da sociedade civil ou do chamado "terceiro setor", porém posteriormente foram incorporadas iniciativas oriundas do setor público e, também, de algumas empresas mercantis. Apesar das diferentes abordagens, de modo geral, acredita-se atualmente que os três setores podem gerar inovação social, principalmente quando colaboram entre si (EZPONDA; MALILLOS, 2011). "As inovações que começam num setor podem ser assumidas por outros, e com frequência as inovações mais excitantes ocorrem nas fronteiras entre setores" (MULGAN, 2010, p. 59).

Além da importância da parceria entre o setor público (por meio de políticas e de modelos de serviços), o setor privado (como nos exemplos das finanças éticas, da responsabilidade social das empresas e de novos negócios colaborativos) e o terceiro setor para a inovação social, Mulgan (2010) enfatiza o papel crítico da família na criação de movimentos sociais, como o slow food, e aqueles em prol dos direitos dos portadores de necessidades especiais.

Nesta perspectiva, raramente as inovações sociais são apenas top down ou bottom up. É reforçada a necessidade de parceria entre, de um lado, as pequenas organizações, os grupos e os indivíduos, em razão da sua elevada criatividade, mobilidade e rapidez, e, de outro, as grandes organizações, como o Governo, as empresas e as organizações sem fins lucrativos de grande porte, que, apesar de serem menos criativas, têm elevada capacidade para implementação, resiliência, sustentação e escala para fazerem as coisas acontecerem.

$\mathrm{Na}$ visão de Ionescu (2015), como as estruturas e as políticas existentes não conseguem resolver problemas prementes, deposita-se esperança na inovação social. As pessoas tornaram-se mais conscientes da importância de se organizarem para encontrar soluções para os desafios enfrentados pela sociedade. Essa tomada de consciência foi fundamental para que novas organizações ou redes de colaboração fossem desenvolvidas com o objetivo de amenizar a pobreza e a exclusão social.

Tais respostas seguem diferentes trajetórias de acordo com os recursos disponíveis e a interferência de fatores propulsores e/ou restritivos. No entanto, citando Bacon et al. (2008), Oliveira e Breda-Vázquez (2012) afirmam que, independentemente das particularidades, é possível identificar padrões que resultam em fases semelhantes do ciclo de vida das inovações sociais, conforme indicado no Quadro 1. Em consonância com os padrões citados, a inovação social geralmente inclui exigências de mudança, o surgimento aleatório de novas ideias como uma resposta às novas necessidades e eventual desenvolvimento, teste e integração. 
Quadro 1 - Fases do ciclo de vida da inovação social

\begin{tabular}{|c|c|c|c|}
\hline & Fase & Descrição & Obstáculo \\
\hline 0 & Latente & $\begin{array}{l}\text { Identificação de uma necessidade social. } \\
\text { Lançamento de novas ideias. }\end{array}$ & \\
\hline 1 & $\begin{array}{l}\text { Concepção e } \\
\text { desenvolvimento }\end{array}$ & Discussão e seleção de ideias. & $\begin{array}{l}\text { Abandono precipitado de ideias } \\
\text { promissoras. }\end{array}$ \\
\hline 2 & Mobilização & $\begin{array}{l}\text { Adaptação do contexto institucional para a } \\
\text { inovação. }\end{array}$ & $\begin{array}{l}\text { Falta de suporte, recursos ou } \\
\text { liderança adequada. }\end{array}$ \\
\hline 3 & Generalização & $\begin{array}{l}\text { Incorporação da inovação social para as práticas e } \\
\text { rotinas do seu contexto organizacional. }\end{array}$ & $\begin{array}{l}\text { Oposição movida por interesses } \\
\text { estabelecidos. }\end{array}$ \\
\hline 4 & Disseminação & $\begin{array}{l}\text { Transferência da inovação para outros contextos } \\
\text { institucionais. }\end{array}$ & $\begin{array}{l}\text { Enraizamento de práticas anteriores. } \\
\text { Fragmentação institucional. }\end{array}$ \\
\hline
\end{tabular}

Fonte: Adaptado de Bacon et al. (2008 apud OLIVEIRA; BREDA-VÁZQUEZ, 2012, p. 525).

Assim como foram apontados obstáculos à continuidade nas etapas da inovação social, Oliveira e BredaVázquez (2012) destacam os seguintes facilitadores: a) efeitos escalares, obtidos com o apoio de atores estratégicos, que podem facilitar a sua difusão; b) diversidade de atores, possibilitando coalizões heterogêneas, que podem contribuir para a sustentabilidade e a disseminação de inovações sociais; c) redes, que podem estabelecer laços mais fortes entre inovadores sociais e legisladores; d) adequado sistema de comunicação, que pode minimizar as desconfianças e outros obstáculos à difusão da inovação social; e) recursos, como os financeiros, em que, de um lado, sua inexistência pode ser um gatilho para o desenvolvimento da inovação social em fases iniciais do ciclo e, de outro, tornam-se indispensáveis nas fases posteriores, principalmente na de difusão; e f) a própria natureza da inovação social, que, quando dotada de certas características, pode facilitar o caminho para os processos de difusão.

Como critérios para avaliar a prática de inovação social e os seus impactos, Parente et al. (2014) propõem escala, alcance e ressonância, utilizados por Nilsson (2003). A escala relaciona-se ao número de pessoas e área geográfica abrangida. O alcance, à multiplicidade de dimensões sociais abrangidas pelos processos, que se correlacionam e resultam em melhorias inter-relacionadas. A ressonância refere-se à intensidade com que as práticas ou processos da inovação social passam a integrar-se nas estruturas mentais e nas práticas sociais, promovendo uma reinterpretação e uma apropriação que favoreça a sua reprodução. Muitos autores definem este último indicador como replicabilidade, quando há replicação da inovação de um contexto a outros.

No entanto, Parente et al. (2014) consideram que a replicabilidade é um indicador de ressonância, ideia que favorece uma perspectiva sistêmica da capacidade de expansão ou replicação, afastando as soluções pré-fabricadas e favorecendo as soluções flexíveis e enraizadas nas comunidades onde são implementadas.

A replicação parece estar mais associada à difusão das chamadas "tecnologias sociais", termo amplamente utilizado no contexto brasileiro. Baumgman (2006) considera que o conceito de tecnologia social compreende os produtos, as técnicas ou as metodologias reaplicáveis, desenvolvidos na interação com a comunidade e que representem efetivas soluções de transformação social. É a base em torno da qual é possível articular uma ampla rede de atores sociais. No entanto, a inovação social com base em tecnologias sociais precisa ser estruturada em modelos flexíveis, pois nem tudo que é viável em um lugar e para determinada situação o será para outra, mesmo que semelhante.

É na busca por ressonância das inovações sociais desenvolvidas que Diogo (2010) destaca o caráter multidimensional das redes interorganizacionais que, ao envolverem indivíduos/agentes, organizações, voluntários, parceiros e patrocinadores, potencializam o impacto nas dinâmicas sociais.

Brass et al. (2004, p. 795) definem redes "como um conjunto de nós e o conjunto de laços que representa alguma relação ou falta de relação entre os nós". São considerados como nós o conjunto de atores envolvidos, sejam eles indivíduos, unidades de trabalho ou organizações. Como laços são consideradas 
as relações que são mantidas ao longo do tempo, estabelecendo assim um padrão relativamente estável de inter-relações de rede.

As redes interorganizacionais envolvem relacionamentos cooperativos de longo prazo entre organizações e fornecedores, clientes, concorrentes e outros atores organizacionais nos quais as organizações mantêm controle sobre seus próprios recursos, mas decidem conjuntamente sobre seu uso. Nessas parcerias, os problemas são tipicamente resolvidos por meio de discussões e as regras e normas de reciprocidade garantem a cooperação. (BRASS et al., 2004).

Da perspectiva de Brass et al. (2004), dentre os principais motivos para a cooperação interorganizacional estão a aquisição de recursos, a busca por reduzir a incerteza, para aumentar a legitimidade e alcançar objetivos coletivos. Além disso, possibilita acesso a informações, recursos, mercados e tecnologias; com vantagens de economias de aprendizagem, escala e escopo; e permite às organizações o alcance de objetivos estratégicos, partilhando investimentos e riscos. Quandt (2012) considera que a eficácia das redes depende da capacidade de integrar tipos diferentes de informação codificada e conhecimento tácito, e difundi-los por meio de interações entre diferentes tipos de agentes.

Enquanto espaço socialmente constituído, as redes de cooperação pressupõem uma relação de colaboração e interdependência. Se, por um lado, com o isolamento, não podem ser desenvolvidos os recursos necessários à organização, por outro, através da união e colaboração, tais recursos podem ser mais facilmente acessados. (KLANOVICZ et al., 2018). Os laços de rede transmitem informações e são considerados canais de informações especialmente influentes porque fornecem informações relevantes e confiáveis. Assim, as redes aceleram a difusão de informações e afetam o comportamento de seus nós a partir da adoção mimética de práticas. (BRASS et al., 2004).

Ademais, a rede amplia o potencial da estrutura organizacional para além da organização, e eventualmente além do seu território e setor. Por meio de redes o contexto de atuação se amplia com as relações simultâneas e interdependentes entre organizações de naturezas distintas (QUANDT, 2012).

O estabelecimento de redes interorganizacionais é indispensável para a definição e o estabelecimento de políticas públicas. A produção destas políticas envolve tanto organizações públicas, quanto privadas, não sendo mais um assunto exclusivo de uma hierarquia governamental administrativa integrada. Com frequência, essas "configurações modernas de formulação de políticas públicas são de tal maneira híbrida ou heterárquica, que os níveis não são sempre claramente separados, mas, ao contrário, atores de diferentes níveis com frequência cooperam” neste processo (SCHNEIDER, 2005, p. 37-38).

Como consequência, "há uma tendência para acrescente interdependência funcional entre atores públicos e privados na consecução de uma política, e apenas por meio das redes de políticas pode-se garantir a mobilização dos recursos dispersos e dar uma resposta eficaz" a determinados projetos (FREURY, 2005, p. 79). Deste modo, a gestão de redes apresenta-se como "uma modalidade administrativa mais compatível com uma sociedade plural e democrática, em que o exercício do poder público cada vez mais se dá de forma descentralizada e com menor protagonismo do governo central" (FREURY, 2005, p. 82).

No campo da economia solidária, Mance (2003 apud CRUZ, 2009) afirma que no que se diz respeito aos aspectos econômicos, as redes são estratégicas para conectar empreendimentos solidários de produção, comercialização, financiamento e consumidores, dentre outras organizações populares, realimentando-se e crescendo em conjunto. Como objetivos das redes de economia solidária citam-se: incrementar a produção de produtos finais, insumos e serviços; gerar novos postos de trabalho e promover a distribuição de renda; e garantir as condições econômicas para o exercício das liberdades públicas e privadas eticamente exercidas.

Na visão de Cruz (2009), o Estado é o elo mais complexo no processo de criação de redes de economia solidária. Mesmo não participando diretamente do processo, ele desempenha papel decisivo, por dispor 
de um excepcional arsenal de instrumentos de ação política, social e econômica. Desse modo, as redes de economia solidária devem estar preparadas para estabelecer relações concretas com o Poder Público, que podem considerar a colaboração e a cooperação abertas a processo de enfrentamento explícito, com fundamento na mobilização política dos trabalhadores associados e de seus aliados.

Da perspectiva de Canestrino et al. (2016), as pesquisas recentes sugerem que atores envolvidos em inovações sociais provavelmente usarão redes para acessar informações, financiamento e contatos comerciais úteis, ainda mais que outros atores envolvidos em negócios. Deste modo, a inovação social poderia ser melhor investigada a partir da abordagem da rede social. A análise de redes sociais para a inovação social chama a atenção para relacionamentos entre os atores que podem levar a resultados bemsucedidos. Dá ênfase, portanto, ao conjunto de relações às quais os atores adquirem informação, capital, habilidades e recursos variados.

A adoção de uma perspectiva de redes sociais nos permite entender melhor o caminho criado pelas redes para a criação e difusão de novas alternativas. $\mathrm{Na}$ fase inicial da inovação social, as relações e os contatos pessoais são muito importantes para identificar novas idéias, ferramentas e estratégias para iniciar um processo de mudança social. Assim, a inovação social raramente é o resultado de uma iniciativa individual. Mais frequentemente, resulta de esforços conjuntos de muitos atores, ligados de maneira diferente e inspirados pelos mesmos valores. Nos estágios seguintes, as redes tornam-se essenciais para a obtenção de fundos e outros recursos ao fomentarem relações entre organizações, setores e pessoas que podem financiar a iniciativa. (CANESTRINO et al., 2016).

Por sua vez, Pel et al. (2018) afirmam que inovações sociais encontram terreno fértil quando há colaborações intensivas com autoridades locais, organizações não governamentais, organizações comunitárias, empresas e instituições educacionais. Estas colaborações permitem a cocriação de projetos, práticas e novos modos de organização de governança participativa, além de contribuir para a formação da identidade local e para o intercâmbio local de conhecimentos e habilidades. Além da conectividade local, também é destaca a importância de conectividade translocal ou transnacional por meio de federações, plataformas ou movimentos internacionais. Essas redes contribuem para o desenvolvimento de uma massa crítica para práticas alternativas, para a construção da voz política translocal e para a troca de conhecimentos. As conexões internacionais também são frequentemente ativos importantes para a aquisição de fundos.

Como fecho teórico, cabe destacar o papel das redes locais iniciais e das políticas nacionais como parte da ampliação da inovação social. Quanto mais fronteiras ultrapassadas, mais amplo e profundo o impacto e mais provável a inovação resultar em mudança transformadora. As redes, com a sua capacidade para transpor, adaptar e moldar a mudança, podem ser uma maneira das organizações lidarem com problemas complexos. Além disso, podem ser cruciais para a capacidade dos seres humanos inovarem coletivamente, dando respostas necessárias para iniciar e apoiar a mudança (MOORE; WESTLEY, 2011).

\section{Procedimentos metodológicos}

O estudo, de natureza qualitativa, utilizou-se de pesquisa documental, observação direta e entrevistas semiestruturadas com informantes chave. A seleção dos entrevistados seguiu os critérios disponibilidade e relevância para a organização e para o estudo (seleção por conveniência, da perspectiva de Merriam (1998)).

Foi elaborado roteiro para as entrevistas semiestruturadas realizadas com dirigentes, parceiros, associados e funcionários da organização. Apesar de as perguntas terem sido predefinidas, à medida que as entrevistas foram realizadas, o roteiro foi aperfeiçoado em função da necessidade de obter outros tipos de dados (GODOY, 2006). As entrevistas foram realizadas individualmente. No entanto, o foco da 
investigação e as unidades de análise estavam centrados no funcionamento coletivo da organização (PARENTE; QUINTÃO, 2014). Foram entrevistados 10 sujeitos, cujos perfis seguem descritos no Quadro 2.

Quadro 2 - Perfil dos Entrevistados do IABS

\begin{tabular}{|c|c|c|c|c|}
\hline Entrevistado & Função & Idade & $\begin{array}{c}\text { Tempo na } \\
\text { organização }\end{array}$ & Escolaridade \\
\hline $\mathbf{A}$ & Diretor-presidente & $\begin{array}{c}43 \\
\text { anos }\end{array}$ & 11 anos & $\begin{array}{l}\text { Graduação e Mestrado em Engenharia de } \\
\text { Pesca; Doutorado em Desenvolvimento } \\
\text { Sustentável; Pós-Doutorado em Gestão de } \\
\text { Conflitos Socioambientais. }\end{array}$ \\
\hline B & Presidente do Conselho & $\begin{array}{c}56 \\
\text { anos }\end{array}$ & 13 anos & Oceanógrafo \\
\hline C & Diretor de comunicação & $\begin{array}{c}37 \\
\text { anos } \\
\end{array}$ & 13 anos & $\begin{array}{l}\text { Analista de sistemas; Mestrado em } \\
\text { Comunicação. }\end{array}$ \\
\hline $\mathbf{D}$ & $\begin{array}{l}\text { Diretora administrativa } \\
\text { financeira }\end{array}$ & $\begin{array}{c}32 \\
\text { anos }\end{array}$ & 3 anos & Graduação em Administração \\
\hline $\mathbf{E}$ & Diretor técnico & $\begin{array}{c}38 \\
\text { anos }\end{array}$ & 8 anos & $\begin{array}{l}\text { Graduação em Ciência da Computação; } \\
\text { Especialização em gestão governamental. }\end{array}$ \\
\hline $\mathbf{F}$ & $\begin{array}{l}\text { Coordenadora do Núcleo } \\
\text { de Meio Ambiente e } \\
\text { Unidade de Conservação } \\
\text { (Belo Horizonte) }\end{array}$ & $\begin{array}{c}34 \\
\text { anos }\end{array}$ & 3 anos & $\begin{array}{l}\text { Bióloga; Especialização em Administração e } \\
\text { Manejo de Unidade de Conservação; } \\
\text { Mestrado em Geografia. }\end{array}$ \\
\hline G & $\begin{array}{c}\text { Consultor de licitações e } \\
\text { contratos e Membro do } \\
\text { Conselho Fiscal }\end{array}$ & $\begin{array}{c}69 \\
\text { anos }\end{array}$ & 9 anos & $\begin{array}{l}\text { Bacharel em Administração; Especialização } \\
\text { em Auditoria e Análise Organizacional }\end{array}$ \\
\hline $\mathbf{H}$ & Secretária & $\begin{array}{c}38 \\
\text { anos }\end{array}$ & 4 anos & Segundo grau \\
\hline $\mathbf{I}$ & Diretor da Editora IABS & $\begin{array}{c}35 \\
\text { anos }\end{array}$ & 8 anos & Graduação em Turismo \\
\hline $\mathbf{J}$ & $\begin{array}{l}\text { Coordenador de agricultura, } \\
\text { recursos naturais e } \\
\text { adaptação a mudanças } \\
\text { climáticas da instituição } \\
\text { parceira IICA (Instituto } \\
\text { Interamericano de } \\
\text { Cooperação para a } \\
\text { Agricultura) }\end{array}$ & $\begin{array}{c}63 \\
\text { anos }\end{array}$ & $\begin{array}{c}3 \text { anos } \\
\text { (conhece) }\end{array}$ & $\begin{array}{l}\text { Engenheiro Civil; Mestrado em Biologia } \\
\text { Aplicada; Doutorado em Recursos Hídricos }\end{array}$ \\
\hline
\end{tabular}

Fonte: Elaborado pelos autores, a partir de dados da pesquisa.

De posse dos dados, na etapa de análise qualitativa, foram recuperados os diálogos gravados e foi feita sua transcrição, enfatizando alguns momentos especiais registrados na memória ou anotados para o momento da análise final. Posteriormente, os significados nucleares das respostas foram colocados em uma matriz de dupla entrada - em uma coluna as falas dos entrevistados, aproximadas por características de estratificação; em outra, as categorias de análise, dando corpo ao que se designa como análise de conteúdo (BARDIN, 1977). Por fim, foi realizada a análise do conjunto, visualizando os fatos de evidência relativos a cada entrevistado, no conjunto das suas respostas, e refletindo sobre todo o conjunto das entrevistas (MATTOS, 2006). Ademais, as reflexões foram enriquecidas pela análise dos documentos obtidos, de um inquérito complementar, das anotações do caderno de campo e das fotografias tiradas dos espaços físicos da organização e de seus integrantes em reuniões de trabalho. Posteriormente à sistematização dos dados, estes foram analisados à luz do referencial teórico, possibilitando o desenvolvimento de conclusões sobre a investigação. Desse modo, o estudo pode ser considerado como de natureza descritiva e interpretativa. 


\section{O IABS e o Desenvolvimento de Inovações Sociais}

O IABS teve sua história iniciada em 2003, como empresa de consultoria sediada em Brasília, DF, que trabalhava com projetos de intervenção direcionados à criação de peixes, da qual faziam parte aqueles que vieram a ser seus futuros fundadores. A decisão por fundar uma organização sem fins lucrativos se deu pelo fato de a empresa ter ampliado significativamente o número de associados e de seu campo de atuação ter se voltado para a área social. Como efeito, a empresa foi formalizada como uma associação, conquistando também o estatuto de Organização da Sociedade Civil de Interesse Público (OSCIP).

Como grande parte de seus fundadores era graduada em cursos relacionados à pesca e à aquicultura, inicialmente, o escopo de atuação do Instituto se restringia a estas áreas. A diversificação de suas atividades iniciou-se em 2006, período em que passou a contar com recursos financeiros da Cooperação Espanhola. Mesmo com a ampliação de seu escopo, na visão do Entrevistado A, o IABS tem como foco de atuação o desenvolvimento local, por meio do planejamento setorial e territorial, atuando principalmente em regiões com baixos índices de desenvolvimento humano.

Além da sede em Brasília, onde também funciona a Editora IABS, registrada como figura jurídica independente, foi necessário montar escritórios em outros estados, para dar suporte aos consultores que atuavam diretamente na execução dos projetos. O primeiro escritório foi estruturado em Maceió e o segundo em Belo Horizonte. Está prevista a abertura de um terceiro na cidade do Rio de Janeiro.

No que diz respeito à sua estrutura organizacional, além dos Conselhos legais, como o Conselho Administrativo e o Conselho Fiscal, o IABS conta com outros, estruturados como núcleos temáticos. O Núcleo Decisor, formado por sete pessoas - representantes dos conselhos, diretor de comunicação e diretor da Editora -, é responsável pelas decisões rotineiras. O Núcleo Integrador, cujo objetivo é integrar os escritórios com os demais grupos temáticos e com a Direção, reúne todos os membros do Conselho Deliberativo e da Diretoria e os coordenadores de escritórios locais. Eles se reúnem presencialmente uma vez por trimestre e, mensalmente, por meio virtual (Skype).

Por mais que os integrantes do IABS tenham considerado nas entrevistas que o foco do Instituto não seja o desenvolvimento de inovação social, após explicado o conceito utilizado na pesquisa (DIOGO, 2010; MOULARTT et al., 2013), os entrevistados afirmaram que, ao buscar melhorias da qualidade de vida da população com quem atua, articulando parcerias para o desenvolvimento de conhecimentos, produtos e intervenções, tornou-se comum que ações socialmente inovadoras fossem desenvolvidas.

Dentre as ações consideradas como socialmente inovadoras, estão as relacionadas com os projetos que resultaram no Centro Xingó, na depuradora de ostras de Cururipe (Estado do Alagoas), no desenvolvimento do turismo sustentável no Rio São Francisco, na criação de diferentes tipos de cisternas para a captação de água em comunidades semiáridas, na criação do aplicativo "Pescando com Rede 3G" e na criação de unidades de conservação em Minas Gerais.

A disseminação e a implementação de novas tecnologias para a construção de cisternas de captação foi o projeto de maior abrangência, visibilidade e volume de recursos implementado pelo IABS. Este projeto faz parte um programa ainda maior validado pelos movimentos sociais e incorporado pelo Governo como política pública. Tal programa tem por objetivo proporcionar à população do semiárido o acesso à água por meio de recursos e do desenvolvimento e disseminação de novas tecnologias que facilitem sua captação e armazenamento.

O projeto Cisternas foi desenvolvido com o financiamento da Agencia Española de Cooperación Internacional para el Desarrollo (AECID), que buscou incrementar recursos no "Programa Um Milhão de Cisternas", desenvolvido pelo Ministério do Desenvolvimento Social e Agrário (MDS), em parceria com a Associação Programa Um Milhão de Cisternas para o Semiárido (AP1MC), vinculada à Articulação 
no Semiárido Brasileiro (ASA). O IABS foi inserido no Programa após a entrada da AECID, com quem tinha um histórico de trabalho.

Outro projeto destacado foi o desenvolvido para a articulação do Centro Xingó de Convivência com o Semiárido, com sede no estado do Alagoas, considerado pelos entrevistados como um centro promotor de inovações sociais. A cargo da gestão do IABS e com investimentos da Cooperação Espanhola, o Centro busca a "geração, difusão e troca de conhecimentos, práticas e experiências sustentáveis para promoção de convivência harmônica e solidária com o Semiárido" (XINGÓ, 2016). O Comitê Gestor é formado por representantes de diferentes organizações sociais - IABS, Companhia Hidro Elétrica do São Francisco (CHESF), IICA, Secretaria de Estado da Agricultura, Pecuária, Pesca e Aquicultura do Estado do Alagoas, Ministério do Meio Ambiente, AECID e Companhia de Desenvolvimento dos Vales do São Francisco e do Parnaíba (CODEVASF) - e de pesquisa, como: Empresa Brasileira de Pesquisa Agropecuária (EMBRAPA), Universidade Federal de Alagoas (UFAL), Instituto Federal de Alagoas e Universidade Federal de Pernambuco. Além do desenvolvimento de pesquisas, são ministrados cursos para a população local, tais como, criação de galinha caipira, ovinocaprinocultura, manejo do solo, silagem e tecnologias sociais.

A estrutura do Centro Xingó conta com alojamentos, espaços para alimentação, auditório e salas da aula. Há também espaços para demonstrativo de tecnologias sociais, como, biodigestores e cisternas de diferentes tipos. Na visão do Entrevistado C, a articulação do Centro permite a integração de esforços da academia, de instituições públicas, de agricultores, e dos diversos setores da sociedade na busca por desenvolvimento sustentável. Busca abranger todo o semiárido brasileiro, desde Minas ao Ceará.

Também associado ao desenvolvimento e à disseminação de inovações sociais, está o Prêmio Mandacaru. O IABS foi responsável pelas duas edições do referido prêmio, que busca identificar práticas socialmente inovadoras e premiá-las. Por meio deste, as ações ou os projetos premiados recebem um recurso para que seus idealizadores possam desenvolver novos protótipos, tendo em vista sua replicabilidade e escalabilidade. Como afirmou o Entrevistado A, muitas práticas premiadas pelo Prêmio Mandacaru foram implantadas no Centro Xingó como demonstrativos.

No âmbito do turismo, foram desenvolvidos projetos voltados para a dinamização do turismo no Rio São Francisco. Isso resultou em um estudo sobre o alto, médio e baixo São Francisco e na identificação e articulação de empresários para ampliar a visibilidade turística da região. Segundo o Entrevistado D, o projeto teve duração de quatro anos e estava vinculado ao Banco Interamericano de Desenvolvimento (BID). A entrevistada F, que hoje atua como responsável pelo escritório de Belo Horizonte, iniciou suas atividades no IABS por meio deste projeto, capacitando pessoas que trabalhavam com turismo de caverna. Tal capacitação estava associada ao plano de ação nacional com cavernas do São Francisco desenvolvido pelo Centro Nacional de Pesquisa e Conservação de Cavernas (CECAV), outra parceira do Instituto.

Como resultado das atividades voltadas ao turismo e à geração de trabalho e renda, outra inovação social destacada foi a depuradora de ostras, que resultou de um projeto desenvolvido pelo IABS para associar conhecimentos sobre gastronomia com tecnologia de produção de base comunitária. Neste intento, foi montada uma unidade de beneficiamento em Alagoas, onde as ostras produzidas nas comunidades locais passaram a ser depuradas para serem comercializadas com garantia de qualidade.

Ainda no âmbito da pesca, o IABS promoveu o desenvolvimento de um aplicativo capaz de facilitar a pesca e a comercialização do pescado de pescadores indígenas e artesanais da região de Porto Seguro. No âmbito do projeto "Pescando com Rede 3G", tal aplicativo facilitou o planejamento da atividade da pesca e comercialização dos produtos capturados. O projeto foi apoiado pela empresa americana Qualcom, detentora da tecnologia $3 \mathrm{G}$ para celulares. Com o aplicativo, os pescadores passaram a contar com uma ferramenta que era alimentada diariamente e permitia o cálculo dos custos e do volume de peixes adquiridos. O aplicativo permitiu que o pescador calculasse a hora mais adequada para o retorno da 
embarcação, garantindo bons retornos financeiros e a qualidade do pescado. Permitiu também a comunicação direta com os donos de estabelecimentos comerciais locais, fazendo com que mesmo antes de se chegar em terra se efetuasse a venda de toda a produção.

Com a estruturação do escritório de Belo Horizonte, o IABS também conseguiu articular a implantação de planos de manejo de unidade de conservação ambiental, em parceria com o Ministério Público do Estado de Minas Gerais. Neste âmbito, passou a desenvolver ações para o desenvolvimento do território em consonância com os princípios básicos ambientais e sociais. O objetivo foi proporcionar informações para que o território pudesse se desenvolver.

De modo geral, a percepção sobre a escala (NILSON, 2003) obtida pelas ações consideradas como socialmente inovadoras variou significativamente, pois, segundo os entrevistados, a escala depende da abrangência do projeto e do volume de recursos investidos. Grande parte dos projetos desenvolvidos pelo IABS foi considerada como piloto e de base local e, desse modo, de pequena escala. Porém, alguns projetos, como o Cisternas, surtiram impacto em um grande número de beneficiários. No exemplo citado, foram mais de quinze mil cisternas construídas dentro do Programa Um Milhão de Cisternas, beneficiando mais de quinze mil famílias, já que algumas cisternas são escolares.

Apesar de cada projeto ter um foco específico, na maioria das vezes, foram várias as dimensões impactadas, com destaque para: meio ambiente, geração de trabalho e renda, turismo, energia, gestão de conflitos, qualificação e lazer. Diante da complexidade dos problemas, nem sempre suas causas partem apenas de uma dimensão, e as propostas também precisam extrapolar de uma dimensão a outra. Tal fato fez com o IABS buscasse articular ações mais integradas e de maior alcance (NILSON, 2003).

Por mais que grande parte dos projetos tenha sido considerada como piloto, os entrevistados afirmaram que muitas das ações desenvolvidas pelo IABS foram disseminadas e apropriadas em outros contextos (indicador de ressonância, segundo Nilson (2003)). Neste âmbito, ganharam destaque os projetos Cisternas, Centro Xingó e Prêmio Mandacaru. O Prêmio Mandacaru possibilitou, além do mapeamento e da divulgação de boas práticas, recursos para que novos protótipos fossem construídos e difundidos a outras organizações (Entrevistado C). O Centro Xingó possibilitou a realização de seminários, debates e experimentações. Além da disseminação, exerceu forte inspiração para a construção de novos conhecimentos (Entrevistada D). O Projeto Cisterna foi desenvolvido numa diversidade de territórios do semiárido brasileiro, às vezes, com alguma adaptação (Entrevistado I).

A Editora IABS também exerceu importante papel na ressonância das ações implementadas pelo Instituto ao atuar diretamente na edição e publicação dos resultados das intervenções, seja no formato de livros ou de vídeos doados à comunidade ou baixados em seu site (Entrevistado C). Grande parte dessas publicações, além enfatizar as metodologias de intervenção, buscou a divulgação de uma diversidade de tecnologias sociais desenvolvidas, ora pelos beneficiários, ora pelos parceiros ou, até mesmo, pelo IABS. O Prêmio Mandacaru, além de ter estimulado o desenvolvimento, resultou em uma dessas publicações destinadas à facilitação da replicação das tecnologias premiadas.

\section{Importância das redes interorganizacionais para o desenvolvimento das inovações sociais}

Como a maioria dos problemas enfrentados pelo IABS foi considerada como de alto grau de complexidade e diante da escassez de recursos para superá-los, o desenvolvimento de práticas socialmente inovadoras demandou o trabalho em parcerias e em rede de cooperação, principalmente quando eram esperados resultados sustentáveis no longo prazo e em variadas dimensões, reforçando os achados e as teorias de Mulgan (2010), Ezponda e Malillos (2011) e Moulaert et al. (2013). 
No entanto, na visão do Entrevistado A, o IABS não busca a sua inserção em redes formais, tais como a Rede Serrado e a Associação do Semiárido. As redes que participa são mais executivas, com formalizações bilaterais e formalizadas por meio de projetos.

$\mathrm{Na}$ visão dos entrevistados, cada projeto do Instituto requer a articulação de diferentes parceiros, a depender de seu foco e da expertise de cada organização envolvida. Neste sentido, foram destacados os seguintes parceiros do IABS: Instituto Alberto Luiz Coimbra de Pós-Graduação e Pesquisa de Engenharia da Universidade Federal do Rio de Janeiro (COOPE), Universidade Politécnica de Madrid, IICA, Universidade Federal do Cariri, Ministério do Meio Ambiente, Secretaria de Agricultura do Estado de Alagoas, Ministério Público de Minas Gerais, Instituto Estadual de Floresta (IEF) e Universidade Federal de Minas Gerais (UFMG).

Para o Entrevistado A, as redes de parcerias do IABS estão em constante movimento de acordo com o andamento dos projetos. Cada projeto envolve uma rede diferente para a sua execução cujo formato é alterado com a entrada e a saída de organizações e com o maior ou menor engajamento das mesmas. Algumas redes ainda estão em construção como as voltadas para as temáticas turismo e meio ambiente.

$\mathrm{Na}$ visão do Entrevistado G, a estruturação das redes de parcerias permite ao Instituto catalogar todas as organizações com a qual manteve alguma relação prévia. Essa relação pode facilitar o desenvolvimento de ações futuras, até mesmo, na preparação de projetos para editais para financiamentos, por contar com o currículo dos integrantes de diferentes organizações que também colaborarão em sua execução.

Enfatizou-se, no entanto, a necessidade de buscar e valorizar as parcerias estratégicas, pois nem todos os parceiros estão alinhados aos interesses do Instituto. Como foi afirmado pelos entrevistados A, C e D, à medida que a rede crescia tornava-se mais difícil fazer sua gestão e perceber quem estava realmente disposto a colaborar ou quem queria apenas obter benefícios sem grandes investimentos.

Ao trazer o ponto de vista de uma entidade parceira, o Entrevistado J, representante do IICA, afirmou que a aproximação do IABS resultou do fato de as duas organizações possuírem trabalhos semelhantes no âmbito do desenvolvimento e da disseminação de tecnologias sociais para o semiárido brasileiro. Em sua percepção, o IABS, localmente, tem conhecimentos, contatos e experiência em comunicação com a população. Além disso, conhece a melhor forma de garantir que uma ação se concretize de modo permanente. Assim, a parceria com o Instituto facilita a chegada das ações do IICA na ponta, pelo conhecimento sobre a realidade local que aquele possui.

Com a contribuição de parceiros estratégicos, pôde-se observar que, apesar de grande parte das intervenções do IABS ter sido realizada em contextos específicos, uma variedade de inovações sociais alcançou grande escala (NILSSON, 2003; DIOGO, 2010, PARENTE et al., 2014). Os relatos demonstraram que a escala das ações socialmente inovadoras se ampliou significativamente quando a organização trabalhou em rede (MULGAN, 2010; EZPONDA; MALILLOS, 2011), por facilitar a disseminação de experiências de um grupo a outro (BRASS et al., 2004).

$\mathrm{Na}$ visão dos entrevistados, há uma relação direta entre escalabilidade e trabalho em redes efetivas de parcerias, por estas redes ampliarem o potencial de ressonância das ações. Como exemplo, o Entrevistado A cita uma ação considerada pontual, mas que demandou a inclusão de uma variedade de instituições no seu desenvolvimento: trata-se da construção de fogões eco a lenha, cujo objetivo era tornar mais racional o uso da principal matriz energética do nordeste, que é a lenha.

Então, nós estamos trabalhando isto porque o Ministério do Meio Ambiente, IICA e PNUD [Programa das Nações Unidas para o Desenvolvimento]. [...] A lógica é o pessoal da Índia. Como não conheço a Índia, o pessoal de Madri trabalhou com o pessoal da Índia. Então, inclusive, uma aluna que estava fazendo o trabalho lá, do mestrado, vai vir para cá, a partir de agosto, para acompanhar esse processo. A gente está envolvendo a COPPE, está envolvendo o IDS [Instituto para o Desenvolvimento Sustentável] de São Paulo, que é a turma lá da [representante do IDS]. 
Por quê? Porque o IDS tem o foco em transformar algumas ações em políticas públicas. [...]. A Universidade de Madri tem o conhecimento externo e o estudo de avaliação e questão tecnológica não tenho nenhuma, mas a COPPE pode fazer o teste e tem os equipamentos que mede a eficiência do fogo e da fuligem. Agora, eu vou começar isso com quarenta e cinco mil reais que é o que tinha no Ministério do Meio Ambiente para a gente fazer. Então, amanhã já vamos negociar uma segunda etapa com a agência espanhola. [...] As perspectivas através dessa função em rede são maiores (Entrevistado A).

Nestas redes, reforçando a afirmação de Cruz (2009), o Estado foi considerado o principal ator, já que as inovações sociais que obtiveram maior ressonância foram as incorporadas como políticas públicas, como no caso do projeto Cisternas. No entanto, corroborando os achados de Parente et al. (2014), foi frequentemente destacada a necessidade de adequar as ações desenvolvidas às contingências da nova realidade, diante das idiossincrasias de cada contexto, caracterizados por diferentes padrões culturais e pela presença de diferentes demandas e recursos.

O trabalho em rede também estimulou contatos e trocas de experiências com atores externos. Estes contatos foram intensificados pela realização de intercâmbios, visitas, reuniões com representantes de organizações parceiras e participação em palestras, fóruns e congressos. Nestes espaços, tornou-se possível a socialização de saberes considerados como indispensáveis para elaboração de projetos. A construção dessa massa crítica foi tida como indispensável, diante da complexidade dos temas tratados. Caso contrário seria mais difícil e necessitaria de maiores investimentos e tempo para a qualificação dos integrantes da Instituição. Além disso, por restrições financeiras, o IABS não teria condições de ampliar muito sua equipe, necessitando da colaboração de agentes externos.

No Quadro 3, a seguir, é apresentada uma síntese do quadro descrito anteriormente, segundo as etapas de desenvolvimento das inovações sociais propostas por Oliveira e Breda-Vázquez (2012).

Quadro 3 - Reflexões sobre a importância das redes interorganizacionais para o desenvolvimento de inovações sociais no âmbito do IABS

\begin{tabular}{l|l}
\hline \multicolumn{1}{c|}{ Fase } & \multicolumn{1}{c}{ Reflexões } \\
\hline Latente & $\begin{array}{l}\text { Grande parte das demandas foi identificada por parceiros estratégicos que atuam no mesmo campo } \\
\text { do IABS. }\end{array}$ \\
\hline $\begin{array}{l}\text { Concepção e } \\
\text { desenvolvimento }\end{array}$ & $\begin{array}{l}\text { As instituições parceiras desempenharam importante papel nas etapas de estruturação dos projetos, } \\
\text { de formação de equipes multidisciplinares e de acesso a recursos financeiros necessários à execução } \\
\text { das propostas. }\end{array}$ \\
\hline Mobilização & $\begin{array}{l}\text { Tornou-se necessária a mobilização do público beneficiário para a compreensão e realização das } \\
\text { propostas. Nesta etapa foi indispensável a colaboração de instituições públicas e associações locais, } \\
\text { tanto para a articulação política, quanto para o acesso aos recursos necessários. }\end{array}$ \\
\hline Generalização & $\begin{array}{l}\text { O estabelecimento de parcerias deu maior credibilidade à proposta, contribuído para que hábitos } \\
\text { enraizados, descrença e divergência de interesses, considerados como principais gargalos à } \\
\text { incorporação da inovação social, fossem superados. }\end{array}$ \\
\hline Disseminação & $\begin{array}{l}\text { O trabalho em redes facilitou a disseminação das práticas do Instituto por meio do contato com atores } \\
\text { externos, intercâmbios e participação em reuniões, fóruns e congressos. Nessa etapa, o Estado foi } \\
\text { considerado como principal parceiro ao adotar algumas práticas de sucesso como políticas públicas. }\end{array}$ \\
\hline
\end{tabular}

Fonte: Elaborado pelos autores, a partir de dados da pesquisa.

Por fim, a facilitação do acesso a recursos financeiros, foi frequentemente enfatizada nos relatos. Por não ter recursos próprios, tornou-se necessária a articulação junto a órgãos públicos, agências de desenvolvimento, cooperação internacional e, até mesmo, empresas privadas. Ademais, a inclusão de varias instituições de renome, como no caso do IICA, que é um organismo internacional, dá maior credibilidade à proposta e à própria Instituição, obtendo maior legitimidade junto aos demais envolvidos.

Com a necessidade de acesso a um número maior de parceiros, com destaque para o Estado, na visão do Entrevistado B, um fator que impulsionou o desenvolvimento das atividades do IABS foi a localização de sua sede em Brasília, facilitando o acesso à administração pública federal e aos escritórios de agências 
de cooperação internacionais, embaixadas e demais organismos internacionais. A proximidade dessas organizações facilitou a interlocução com seus atores e a proposição da adoção das experiências de sucesso como políticas públicas.

\section{Considerações finais}

Por mais que grande parte das inovações sociais identificadas no âmbito das práticas e projetos desenvolvidos pelo IABS tenha sido experimentada no âmbito local, foram obtidas grandes escalas em relação ao número de impactados, principalmente quando as ações foram desenvolvidas por meio de redes de colaboração. Como principais parceiros foram destacados: Estado, financiadores, universidades ou centros de pesquisa e outras OSCs. Diante da complexidade de grande parte dos problemas enfrentados, as redes foram consideradas como indispensáveis na definição e implementação de estratégias cujos resultados se tornaram sustentáveis no longo prazo e na ampliação do alcance de maior variedade de dimensões impactadas. Também foi destacada a importância das parcerias, por potencializarem a resolução de problemas comuns e o acesso a recursos escassos, com destaque para os financeiros e humanos.

Como efeito, o quadro apontado responde ao questionamento de Bouchard (2012) se as OSCs sozinhas possuem condições de resolver problemas em grande escala. O exemplo tomado como base indica que a resposta é negativa e que, principalmente, sem o apoio do Poder Público haveria dificuldades para a ação. Tal quadro também reforça o modelo de Mulgan (2010) sobre a necessidade de articulação entre os diferentes setores, para que haja, de fato, inovação social.

Apesar de o Estado ter sido apontado como principal parceiro, também foi considerada relevante a atuação de centros de pesquisa e de instituições de apoio, que atuam diretamente na informação e formação dos integrantes do IABS e no desenvolvimento de capacidades básicas necessárias ao processo de inovação social que envolve identificação de problemas prioritários e dos recursos disponíveis, proposição de ideias e definição de estratégias para a superação dos problemas identificados.

Foi identificado que os critérios ressonância e escala da inovação social estão interligados, já que as inovações sociais implementadas como pilotos só ganharam escala quando obtiveram certo grau de ressonância. A obtenção de ressonância também foi considerada extremamente dependente da articulação de redes de parcerias, com destaque para o Estado, cujo poder facilitou a transformação de inovações sociais bem sucedidas em políticas públicas.

As forças restritivas ao desenvolvimento de inovações sociais destacadas pelos entrevistados chamam a atenção para a necessidade de ampliar as fontes de financiamento de práticas socialmente inovadoras. Esta necessidade foi apontada no referencial teórico (BOUCHARD, 2012), porém foi mais bem contextualizada pelo caso aqui analisado, que deixou claro o quanto a crise econômica impactou diretamente as OSCs. Tal crise limitou a articulação direta para o financiamento das atividades perante os ministérios e as agências financiadoras, restringindo o acesso a recursos quando se concorre em editais mais específicos. Em contrapartida, a crise também evidenciou a necessidade de apoio as OSCs, uma vez que estas lidam diretamente com uma parcela considerável do público por ela atingido. Também ficou evidente a necessidade do Instituto diversificar suas fontes de recursos, seja por meio da geração de receitas próprias ou da angariação de contribuições financeiras de empresas privadas ou financiadores individuais.

O contexto de crise econômica impôs uma situação paradoxal, pois foi principalmente neste contexto que as inovações sociais tornaram-se indispensáveis, porém os recursos a elas disponíveis tornaram-se ainda mais escassos. Tal quadro impõe a necessidade de construir uma agenda comum voltada à inovação social que seja partilhada pelos diferentes atores envolvidos: Poder Público, centros de pesquisa e de capacitação, agências internacionais e OSCs. Diante da inexistência de fundos nacionais específicos, cabe às OSCs brasileiras recorrerem à cooperação internacional. Porém, tal opção também tem se tornado 
mais restrita, diante do maior interesse dessas agências por realidades com condições estruturais e sociais ainda piores que a brasileira, como o continente africano.

Para o desenvolvimento de práticas socialmente inovadoras, também se tornou necessário contar com competências de atores externos. Para além do acesso a recursos financeiros, esta foi a segunda razão mais citada para a articulação de redes de parcerias. Desse modo, a necessidade de colaboração de atores externos especifica uma grande lacuna para o desenvolvimento de competências necessárias à inovação social, reforçando a importância das instituições de ensino e de assessoria neste contexto.

A principal contribuição do estudo é a compreensão da inovação social como um conjunto integrado e dinâmico de relações entre atores que interagem para criar e reforçar um ambiente de estimulo à inovação. Assim, revela a necessidade de intervenções que unam entidades que atuem no local para promover o surgimento de ideias, a absorção de novos conceitos e tecnologias, e a mobilização dos recursos necessários. Por sua vez, as instituições governamentais devem ser indutoras e facilitadoras das ações coletivas localizadas, com amplo envolvimento dos diversos atores para garantir sinergias. Este estímulo deve aperfeiçoar a eficiência das interações, facilitar o aprendizado mútuo e reforçar as relações de confiança que são construídas ao longo do tempo (QUANDT, 2012).

\section{Referências}

BAUMGARTEN, Maíra. Ciência, tecnologia e desenvolvimento - redes e inovação social. Parcerias Estratégicas, n. 26, pp. 101 - 123, 2008.

BARDIN, Laurence. Análise de conteúdo. Lisboa - Portugal: Edições 70, Ltda. 1977.

BIGNETTI, Luiz Paulo. As inovações Sociais: uma incursão por ideias, tendências e focos de pesquisa. Ciências Sociais Unisinos, v. 47, n. 1, p. 3-14, 2011.

BOUCHARD; Marie J. Social innovation, an analytical grid for understanding the social economy: the example of the Québec housing sector. Serv Bus. v. 6, p.47-59, 2012.

BRASS, D. J.; GALASKIEWICZ, J.; GREVE, H. R.; TSAI, W. Taking stock of networks and organizations: a multilevel perspective. Academy of Management Journal, v. 47, n. 6, pp. 795-817, 2004.

CANESTRINO, Rossella et al. Networks for Social Innovation: Devoting "Learning Spaces" to Social Aims. In: 11th International Forum on Knowledge Asset Dynamics (IFKAD 2016). Anais... 2016.

CRUZ, Antônio. Redes de economia solidária - papéis e limites de atores envolvidos: trabalhadores, universidade e Estado. In: Seminário Internacional "La construcción de conocimientos y prácticas sobre laeconomía social y solidaria en América Latina y Canadá". Anais ... Buenos Aires: CESOT/FCE/UBA, 2009.

DEFOURNY, Jacques. Economia Social. In: CATTTANI, Antonio D. et al. Dicionário Internacional da Outra Economia. Gráfica de Coimbra Ltda: Coimbra, 2009.

DIOGO, Vera. Dinâmicas de Inovação Social e suas implicações no Desenvolvimento Espacial. Três Iniciativas do Terceiro Sector no Norte de Portugal. Dissertação de Mestrado em Riscos, Cidades e Ordenamento do Território. 2010.

DOWBOR, Ladislau. Inovação Social e Sustentabilidade. In: FARFUS, Daniele et al. Inovação Social. Curitiba: SESI/SENAI/IEL/UNINDUS, v. 2., 2007. 
EZPONDA; Javier E.; MALILLOS; Lucía M. Cambio de Paradigma em los Estudios de Innovación: El giro social de lãs políticas europeas de innovacion. ARBOR- Ciencia, Pensamiento y Cultura. v.187, n. 752, 2011, p. 1031-1043.

FLEURY, Sonia. Redes de políticas: novos desafios para a gestão pública. Administração em Diálogo. São Paulo, n. 7, 2005, p. 77-89.

FRAZÃO, Nuno; CARVALHO; Isabel L.; CARLOS; Filipa. Social Innovation in Cidadania Ativa Programme Projects. Calouste Gulbenkian Foundation. Lisboa. 2015.

GODOY, Arilda S. Estudo de caso qualitativo. In: GODOI, C. K., BANDEIRA-DE-MELO, R.; SILVA, A. B. Pesquisa Qualitativa em Estudos Organizacionais: paradigmas, estratégias e métodos. São Paulo: Saraiva, 2006.

IONESCU, C. About the conceptualization of social innovation. Theoretical and Applied Economics, v. 22, n. 3, p. 53-62, 2015.

KLANOVICZ, C.; VERSCHOORE FILHO, J. R. S.; FRANZATO, C. Práticas Estratégicas de Negociação em Redes de Cooperação. Revista de Administração FACES Journal, v. 17, n. 1, p. 4869, 2018.

KLEIN; Juan-Luis. Introduction: social innovation at the crossroads between science, economy and society. In: MOULAERT, Frank; MACCALLUM; Diana; MEHMOOD, Abid; HAMDOUCH; Abdelillah. The International Handbook on Social Innovation. Cheltenham - UK: Edward Elgar, 2013.

; FONTAN, Jean-Marc; HARRISSON, Denis; LEVESQUE; Benoit. The Quebec System of Social Innovation: a focused analysis on the local develop ment field. Finisterra, n. 47, v. 94, 2012, pp. $9-28$.

MATTOS, Pedro Lincoln. Análise de entrevistas não estruturadas: da formalização à pragmática da linguagem. In: GODOI, C. K., BANDEIRA-DE-MELO, R.; SILVA, A. B. Pesquisa Qualitativa em Estudos Organizacionais: paradigmas, estratégias e métodos. São Paulo: Saraiva, 2006.

MEHMOOD, A.; PARRA, C. Social innovation in an unsustainable world. In: MOULAERT, Frank; MACCALLUM; Diana; MEHMOOD, Abid; HAMDOUCH; Abdelillah. The International Handbook on Social Innovation. Cheltenham - UK: Edward Elgar, 2013.

MERRIAM, S. Designing the study and selecting a sample. In: study applications in education. San Francisco: Jossey-Bass, 1998.

Qualitative research and case

MOORE, Michele-Lee; WESTLEY, Frances. Surmountable chasms: networks and social innovation for resilient systems. Ecology and Society, v. 16, n. 1, 2011. Disponível em: <http://www.ecologyandsociety.org/vol16/iss1/art5/>. Acesso em: 06 de out. de 2015.

MOULAERT, Frank; MACCALLUM, Diana; HILLIER, Jean. Social Innovation: intuition, precept, concept, theory and practice. In: MOULAERT, Frank; MACCALLUM; Diana; MEHMOOD, Abid; HAMDOUCH; Abdelillah. The International Handbook on Social Innovation. Cheltenham - UK: Edward Elgar, 2013.

MULGAN, Geoff.. Inovação social. In: AZEVEDO, Carlos; FRANCO; Raquel C.; MENEZES, João W. Gestão de Organizações Sem Fins Lucrativos: o desafio da inovação social. Porto: Uniarte Gráfica S. A. 2010. pp. 51-74.

NILSSON, W. O. Social Innovation: an exploration of the literature. McGill University. 2003. 
OLIVEIRA, Carlos; BREDA-VÁZQUEZ, Isabel. Creativity and Social Innovation: What Can Urban Policies Learn from Sectoral Experiences? International Journal of Urban and Regional Research, v. 36, n.3, 2012, p. 522-38;

PARENTE, Cristina; MARCOS, Vanessa; DIOGO, Vera. Sobre inovação e empreendedorismo social. In: PARENTE, Cristina. Empreendedorismo Social em Portugal. Porto: Universidade do Porto. 2014.

; QUINTÃO, Carlota. Uma abordagem eclética ao empreendedorismo social. In: PARENTE, Cristina. Empreendedorismo Social em Portugal. Porto: Universidade do Porto. 2014. Cap. 1.

PEL, B. et al. Unpacking the Social Innovation Ecosystem: a typology of empowering network constellations. . In: 10TH INTERNATIONAL SOCIAL INNOVATION RESEARCH CONFERENCE SEPTEMBER 3RD -5TH 2018, Heidelberg (GER). Anais... 2018.

QUANDT, C. O. Redes de cooperação e inovação localizada: estudo de caso de um arranjo produtivo local. RAI - Revista de Administração e Inovação, v. 9, n. 1, p. 141-166, 2012.

RODRIGUES, Andrea L. Modelos de Gestão e Inovação Social em Organizações Sem Fins Lucrativos: Divergências e Convergências entre Nonprofit Sector e Economia Social. In: Encontro da Associação Nacional dos Programas de Pós-Graduação e Pesquisa em Administração, 30, 2006, Salvador. Anais..., Salvador: ANPAD, 2006. 1 CD ROM.

SCHNEIDER, V. Redes de políticas públicas e a condução de sociedades complexas. Civitas - Revista de Ciências Sociais, v. 5, n. 1, jan-jun., 2005, p. 29-58.

XINGÓ. Centro Xingó de Convivência com o Semiárido. Disponível em: < http://xingo.com.br/>. Acesso em: 29 de jun. de 2016. 